\title{
Comparison of Greater Palatine Nerve Block with Intravenous Fentanyl for Postoperative Analgesia Following Palatoplasty in Children
}

\author{
Amol Singam ${ }^{1}$, Saranya Rallabhandi², Tapan Dhumey ${ }^{3}$ \\ ${ }^{1}$ Department of Anaesthesiology, JNMC, DMIMS, Sawangi Meghe, Wardha Maharashtra, India. \\ 2Department of Anaesthesiology, JNMC, DMIMS, Sawangi Meghe, Wardha, Maharashtra, India. \\ ${ }^{3}$ Department of Anaesthesiology, JNMC, DMIMS, Sawangi Meghe, Wardha, Maharashtra, India.
}

\section{ABSTRACT}

\section{BACKGROUND}

Good pain relief after palatoplasty is important as inadequate analgesia with vigorous cry leads to wound dehiscence, removal of sutures and extra nursing care. Decrease in oxygen requirement and cardio-respiratory demand occur with good pain relief and also promotes early recovery. Preoperative opioids have concerns like sedation, respiratory depression and airway compromise. Greater palatine nerve block with bupivacaine is safe and effective without the risk of respiratory depression. The study was done to compare pain relief postoperatively with intravenous fentanyl and greater palatine nerve block in children following palatoplasty.

\section{METHODS}

80 children of ASA I \& II, between 1 to 7 years were included and allocated into two groups of 40 each. Analgesic medication was given preoperatively after induction of general anaesthesia, children in Group B received greater palatine nerve block with $2 \mathrm{~mL} 0.25 \%$ inj. Bupivacaine ( $1 \mathrm{~mL}$ on each side) and Group F received $2 \mu \mathrm{g} \mathrm{Kg}{ }^{-1} \mathrm{I} . V$. fentanyl as $2 \mathrm{~mL}$ solution. Assessment of pain was done by FLACC scale and recovery profile by Modified Aldrete Score. Haemodynamic monitoring along with side effects was assessed. Data was analysed using SPSS software (Statistical Package of Social Science) version 17.0. $\mathrm{p}$-value of $<0.05$ was considered significant.

\section{RESULTS}

Patients receiving block showed significantly better recovery profile $(9.22 \pm 0.39)$ vs $(8.78 \pm 0.61)$, duration of analgesia $(482.59 \pm 93.76)$ vs $(174.13 \pm 84.91)$ and less mean paracetamol consumption $(126.66 \pm 18.70)$ vs $(151.79 \pm 60.03)$ with comparable haemodynamics and side effects.

\section{CONCLUSIONS}

Greater palatine nerve block provides effective postoperative pain relief after palatoplasty in children compared to I.V. fentanyl. It is safe, easy to perform, and free of complications.

\section{KEY WORDS}

Greater Palatine Nerve Block, Bupivacaine, Fentanyl
Corresponding Author: Dr. Saranya Rallabhandi, Assisstant Professor, Department of Anesthesiology, AVBRH, DMIMS (DU), Sawangi Meghe, Wardha- 442001, Maharashtra, India. E-mail: saruspicy@gmail.com

DOI: $10.14260 /$ jemds/2020/549

How to Cite This Article:

Singam A, Rallabhandi S, Dhumey $T$. Comparison of greater palatine nerve block with intravenous fentanyl for postoperative analgesia following palatoplasty in children. J Evolution Med Dent Sci 2020;9(35):2526-2530, DOI: 10.14260/jemds/2020/549

Submission 23-05-2020, Peer Review 16-07-2020, Acceptance 23-07-2020, Published 31-08-2020.

Copyright (C) 2020 JEMDS. This is an open access article distributed under Creative Commons Attribution License [Attribution 4.0 International (CC BY 4.0)] 


\section{BACKGROUND}

The common birth defects which require surgical correction are cleft lip and palate. ${ }^{1}$ Cleft palate repair leads to debilitating pain in the postoperative period. Wound dehiscence, discomfort to the child and parent, removal of sutures, intravenous catheters and drains, extra nursing care and adverse physiological effects may occur with inadequate analgesia postoperatively. Decrease in oxygen requirement and cardio-respiratory demands occur with good pain relief and also promotes early recovery. ${ }^{2}$

After palatoplasty, airway compromise occurs postoperatively in infants and neonates due to the narrowing of airway, increase in secretions, pain, and sedation caused by opioids which are routinely used for post-operative analgesia. ${ }^{3,4}$

The use of preoperative opioids results in smoother emergence on extubation that in turn decrease airway trauma and bleeding postoperatively. However, its use in children raises worries about sedation, respiratory depression and consequent airway compromise in postoperative period. ${ }^{5}$ Preincisional greater palatine nerve block with injection bupivacaine is documented to be safe and effective after surgical correction of cleft palate for pain relief without the risk of respiratory depression. ${ }^{6}$ It is also the known fact that preoperative analgesia reduces postoperative analgesic demands significantly.

Bupivacaine is an amide type local anaesthetic with high potency and long duration. ${ }^{7}$ Bupivacaine is safe and gold standard long acting local anaesthetic used for many procedures which are carried out under blocks. Its disadvantages include cardiac toxicity, neurotoxicity and slow wound healing.8,9

Considering all the factors, the study was conducted to compare the quality of pain relief achieved with intravenous fentanyl and local analgesia with greater palatine nerve block postoperatively following palatoplasty in children. The primary outcome was the duration of analgesia and secondary outcomes were to assess recovery profile, haemodynamic parameters i.e., pulse rate and mean blood pressure, complications such as episode of airway obstruction, nausea, vomiting, pruritus and haematoma formation at the site of injection amongst two groups.

\section{METHODS}

The Department of Anaesthesiology, AVBRH, DMIMS, a tertiary care rural hospital in central India, conducted a prospective, randomized, double blind study from August 2015 to August 2017. After obtaining hospital ethics committee permission, parents were informed, and written consent was taken. 80 children of American Society of Anaesthesiologists (ASA) I \& II, between 1 to 7 years, scheduled for palatoplasty were included in this study. Children with history of allergic reaction to local anaesthetics, coagulopathy, combined procedures like palatoplasty with cheiloplasty or submucosal alveolar bone grafting and with major systemic illness compromising any cardiovascular, respiratory or neurological function and other craniofacial anomalies like micrognathia, Pierre Robin Syndrome, Treacher Collins Syndrome were excluded.

Assuming a duration of analgesia of 480 mins and standard deviation of 70 mins by a pilot study, keeping power at $80 \%$ and confidence interval at $95 \%$ (alpha error at 0.05 ), a sample of 34 patients would be required to detect a minimum of $10 \%$ (48 mins) difference in the duration of analgesia between the two groups. We included 40 patients in each group to compensate for possible dropouts.

All the children had pre-anaesthetic assessment prior to the surgery, to allay the anxiety of parents and give preoperative instructions. Detailed history with thorough general, physical and systemic examination was done. Weight $\&$ routine investigations of the patient were noted. All children were kept fasting according ASA guidelines i.e. 2 hours for clear fluids, 4 hours for breast milk and 8 hours for solids.

On the day of surgery, intravenous access was secured in preoperative room and patients were premedicated with intravenous inj. glycopyrrolate $0.004 \mathrm{mg} \mathrm{Kg}^{-1}$ and inj. midazolam $0.1 \mathrm{mg} \mathrm{Kg}^{-1}$ for better cooperation of patient while shifting to operation theatre. On arrival in operation theatre, Ringer's Lactate infusion was started at a rate of $10-15 \mathrm{~mL} \mathrm{Kg}$ $1 \mathrm{hr}^{-1}$. Routine monitors were placed. Pulse rate, blood pressure, $\mathrm{SpO}_{2}, \mathrm{EtCO}_{2}$, blood loss and temperature were monitored throughout the procedure. General anaesthesia induction was done with $50 \%$ oxygen and $50 \%$ nitrous oxide and sevoflurane concentration increasing incrementally, starting from $1 \%$ to 5-6 \%, i.e., $1 \%$ every 6-8 breaths via JR circuit. Endotracheal intubation was facilitated with inj. vecuronium $0.1 \mathrm{mg} \mathrm{Kg}^{-1}$. Intubation was done with the appropriately sized south pole tube and intermittent positive pressure ventilation was given with $33 \%$ oxygen, $66 \%$ nitrous oxide and $1 \%$ sevoflurane. Muscle relaxation was maintained with inj. vecuronium as and when required.

After induction, approximately $5 \mathrm{~min}$ prior to the skin incision, the pain medication was administered. Children were randomly divided into two equal groups of 40 each. Computer generated random number table was used for randomization and the allocation of these numbers was followed by sealed envelope technique.

Group B (block group) children received greater palatine nerve block bilaterally of $2 \mathrm{~mL} 0.25 \%$ inj. bupivacaine $(1 \mathrm{~mL}$ on each side) and I.V. injection of $2 \mathrm{~mL}$ saline.

Group F (fentanyl group) children received $2 \mu \mathrm{g} \mathrm{Kg}^{-1} \mathrm{I} . \mathrm{V}$. fentanyl as a $2 \mathrm{~mL}$ solution and greater palatine nerve block of $2 \mathrm{~mL}$ saline ( $1 \mathrm{~mL}$ on each side).

Infiltration with inj. adrenaline diluted to $5 \mu \mathrm{g} \mathrm{mL}-1$ in normal saline was done around operative site to minimize bleeding.

The greater palatine foramen is located anteriorly to the junction of the hard and soft palate and can be located by pressing a small cotton swab opposite to the first molar reseeding posteriorly till it falls into a depression opposite the posterior part of the second molar tooth, anterior to the junction of the hard and the soft palate. The syringe was positioned from the opposite side of the mouth and at right angle to the target area. ${ }^{10}$ Opposite side was carried out in the same manner. The injection site was massaged, and pressure was applied to prevent the occurrence of hematoma. Surgery was started 5 min later the injection. 


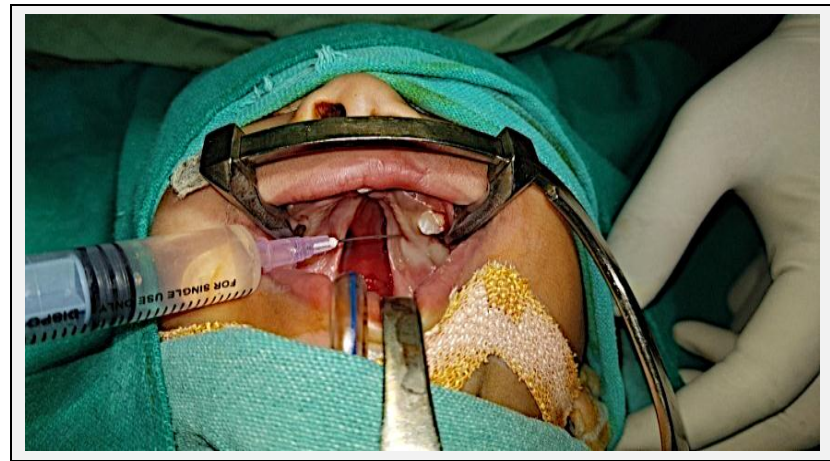

Figure 1. Local Anaesthetic Injection into Greater Palatine Foramen

The same experienced surgeon performed all the procedures. Muscle relaxation was reversed with $0.05 \mathrm{mg}$. $\mathrm{Kg}$ ${ }^{1}$ of inj. neostigmine and $0.008 \mathrm{mg}$. $\mathrm{Kg}^{-1}$ of inj. Glycopyrrolate, at the end of surgery. Haemostasis was inspected and the throat pack was removed. Extubation was done after thorough oral suctioning.

Recovery was assessed by Modified Aldrete Scoring System. ${ }^{11,12}$ In the postoperative ward, they received supplemental oxygen for one hour.

\begin{tabular}{|c|c|c|}
\hline Variable & Score & Interpretation \\
\hline \multirow{3}{*}{ Activity } & 2 & Moves all extremities voluntarily/ on command \\
\hline & 1 & Moves two extremities voluntarily / on command \\
\hline & 0 & Unable to move extremities voluntarily / on command \\
\hline \multirow{3}{*}{ Respiration } & 2 & Able to breathe deeply and cough freely \\
\hline & 1 & Dyspnoeic, shallow breathing \\
\hline & 0 & Apnoeic \\
\hline \multirow{3}{*}{ Circulation } & 2 & Able to breathe deeply and cough freely \\
\hline & 1 & Dyspnoeic, shallow breathing \\
\hline & 0 & Apnoeic \\
\hline \multirow{3}{*}{ Consciousness } & 2 & Fully awake \\
\hline & 1 & Arousable on calling \\
\hline & 0 & Not responding \\
\hline \multirow{3}{*}{$\mathrm{O}_{2}$ Saturation } & 2 & Able to maintain $\mathrm{O}_{2}$ saturation more than $92 \%$ on room ai \\
\hline & 1 & Supplemental $\mathrm{O}_{2}$ required to maintain $\mathrm{SpO}_{2}>90 \%$ \\
\hline & 0 & $\mathrm{SpO}_{2}<90 \%$ with $\mathrm{O}_{2}$ supplementation \\
\hline & & Aldrete Scoring System \\
\hline
\end{tabular}

Maximum score -10 . High Recovery score- 7 to 10 , Low score- $\leq 6$

Pain was assessed at the end of surgery, at the time of extubation and subsequently at an interval of 30 mins for the first 2 hours and then every 2 hours till 12 hours postoperatively using FLACC scale. ${ }^{13}$ It is an interval scale that measures pain in preverbal children by quantifying pain behaviour, ranging from 0 (no pain behaviour) to 10 (the maximum possible pain behaviour).

\begin{tabular}{|c|c|c|c|}
\hline Criteria & Score 0 & Score 1 & Score 2 \\
\hline Face & $\begin{array}{c}\text { No particular } \\
\text { expression or smile }\end{array}$ & $\begin{array}{l}\text { Occasional grimace or } \\
\text { frown, withdrawn, } \\
\text { uninterested }\end{array}$ & $\begin{array}{l}\text { Frequent to constant } \\
\text { quivering chin, } \\
\text { clenched jaw }\end{array}$ \\
\hline Legs & $\begin{array}{l}\text { Normal position or } \\
\text { relaxed }\end{array}$ & Uneasy, restless, tense & $\begin{array}{l}\text { Kicking or legs } \\
\text { drawn up }\end{array}$ \\
\hline Activity & $\begin{array}{l}\text { Lying quietly, normal } \\
\text { position, moves easily }\end{array}$ & $\begin{array}{l}\text { Squirming, shifting, } \\
\text { back and forth, tense }\end{array}$ & $\begin{array}{l}\text { Arched, rigid } \\
\text { or jerking }\end{array}$ \\
\hline Cry & $\begin{array}{l}\text { No cry (awake } \\
\text { or asleep) }\end{array}$ & $\begin{array}{l}\text { Moans or whimpers, } \\
\text { occasional complaint }\end{array}$ & $\begin{array}{l}\text { Crying steadily, } \\
\text { screams or sobs, } \\
\text { frequent complaints }\end{array}$ \\
\hline Consolability & $\begin{array}{l}\text { Content, } \\
\text { relaxed }\end{array}$ & $\begin{array}{l}\text { Reassured by occasional } \\
\text { touching, hugging or } \\
\text { being talked to, } \\
\text { distractible }\end{array}$ & $\begin{array}{l}\text { Difficult to console } \\
\text { or comfort }\end{array}$ \\
\hline \multicolumn{4}{|c|}{ FLACC (Face, Legs, Activity, Cry, Consolability) Scale } \\
\hline
\end{tabular}

Rescue analgesia with inj. paracetamol 10-15 mg. $\mathrm{Kg}^{-1}$ was given, when the pain score exceeded four. The duration for first rescue analgesia and the total number of patients who required postoperative analgesia during the 12 hours period were recorded. Inj. paracetamol was given with a minimum 4hour-time interval between successive doses and rescue analgesia with intravenous fentanyl $0.2 \mu \mathrm{g}$. $\mathrm{Kg}^{-1}$ was given if the pain score was 4 or more within this time interval.

Haemodynamic parameters such as pulse rate and mean blood pressure were assessed during the study. Complications such as episode of airway obstruction due to secretions, bleeding and sedation, nausea, vomiting, pruritus and haematoma formation at the site of injection were also recorded. An anaesthesiologist who was unaware of the allocation of treatment group, recorded and assessed the variables.

\section{Statistical Analysis}

Data was analyzed using SPSS software (Statistical Package of Social Science) version 17.0 (SPSS Inc., Chicago, IL, USA). Numerical variables were presented as mean and standard deviation (SD). Categorical data was summarized as frequency (percentages). Parametric data was analyzed by Student's ttest for in between-groups comparisons. Categorical variables were compared with the chi-square test. $\mathrm{p}$-value of $<0.05$ was considered significant.

\section{RESULTS}

No local or systemic undesirable effects and no complications of the technique were observed in children receiving the block. Hence, there were no dropouts in the study.

\begin{tabular}{|ccccc|}
\hline Variables & Group B & Group F & t-Value & P-Value \\
Age (Years) & $4.82 \pm 1.80$ & $5.10 \pm 0.62$ & 0.93 & 0.35 , NS \\
Weight (Kgs) & $12.02 \pm 3.45$ & $11.50 \pm 4.27$ & 0.59 & 0.55, NS \\
Male/Female & $21 / 19$ & $18 / 22$ & $\chi^{2}-1.24$ & $0.26, \mathrm{NS}$ \\
$\begin{array}{c}\text { Duration of Surgery } \\
\text { (min) }\end{array}$ & $67.01 \pm 12.71$ & $63.66 \pm 13.53$ & 1.14 & $0.12, \mathrm{NS}$ \\
\hline Table 1. Demographic Data of the Patients and Duration of Surgery \\
\hline
\end{tabular}

Both the groups, Group B and Group F, were comparable with respect to demographic characteristics and duration of surgery. (Table 1)

\begin{tabular}{|ccccc|}
\hline Recovery Score & Group B & Group F & $\chi^{2}$ - Value & P-Value \\
7 & 0 & $2(5 \%)$ & 2.02 & 0.15, NS \\
8 & $10(25 \%)$ & $12(30 \%)$ & 0.24 & 0.61, NS \\
9 & $13(32.5 \%)$ & $22(55 \%)$ & 4.06 & 0.04, S \\
10 & $17(42.5 \%)$ & $4(10 \%)$ & 10.76 & 0.001, S \\
\hline \multicolumn{5}{c}{ Table 2. Recovery Scores at Extubation } \\
\hline
\end{tabular}

\begin{tabular}{|ccccc|}
\hline & Group B & Group F & $\boldsymbol{\chi}^{2}$-Value & P-Value \\
Post- op & $4(10 \%)$ & $16(40 \%)$ & 9.40 & $0.002, \mathrm{~S}$ \\
$30 \mathrm{~min}$ & $2(5 \%)$ & $8(20 \%)$ & 4.06 & $0.043, \mathrm{~S}$ \\
$60 \mathrm{~min}$ & $0(0 \%)$ & $4(10 \%)$ & 4.15 & $0.041, \mathrm{~S}$ \\
$90 \mathrm{~min}$ & $1(2.5 \%)$ & $2(5 \%)$ & 0.342 & $0.55, \mathrm{NS}$ \\
$2 \mathrm{hr}$. & $0(0 \%)$ & $4(10 \%)$ & 4.15 & $0.041, \mathrm{~S}$ \\
$4 \mathrm{hr}$. & $1(2.5 \%)$ & $6(15 \%)$ & 3.86 & $0.049, \mathrm{~S}$ \\
$6 \mathrm{hr}$. & $1(2.5 \%)$ & $2(5 \%)$ & 0.342 & $0.55, \mathrm{NS}$ \\
$8 \mathrm{hr}$. & $0(0 \%)$ & $2(5 \%)$ & 2.02 & $0.15, \mathrm{NS}$ \\
$10 \mathrm{hr}$. & $0(0 \%)$ & $1(2.5 \%)$ & 1.00 & $0.31, \mathrm{NS}$ \\
$12 \mathrm{hr}$. & $2(5 \%)$ & $8(20 \%)$ & 4.06 & $0.043, \mathrm{~S}$ \\
\hline Table 3. Number of Patients Having Pain Scores > 4 at Different Time \\
Intervals during the Study Period \\
\hline \multicolumn{5}{c}{} \\
\hline \multicolumn{5}{c}{}
\end{tabular}


Table 2 shows, in Group B, maximum possible recovery score of 10 was achieved by 17 (42.5\%) patients and no patient had recovery score less than 8 , whereas in Group $\mathrm{F}$ only $4(10 \%)$ patients achieved score of 10 . Average recovery score at extubation in Group B and Group F was $9.22 \pm 0.39$ and $8.78 \pm 0.61(\mathrm{t}=3.84, \mathrm{p}=0.0001, \mathrm{~S})$ respectively. The recovery score was better in greater palatine nerve block which was statistically significant.

Table 3 shows, 16 (40\%) patients in Group $\mathrm{F}$ had pain score of 4 or more whereas in Group B only 4 (10\%) patients had pain score of 4 or more, after shifting patient from operation theatre to recovery room. All patients in Group F received rescue analgesia at least once in post- operative period but 29 (72.5\%) patients of Group B did not require additional analgesia during study period. 28 (70 \%) patients required rescue analgesia in 1st hour in Group F compared to only 6 (15\%) in Group B.

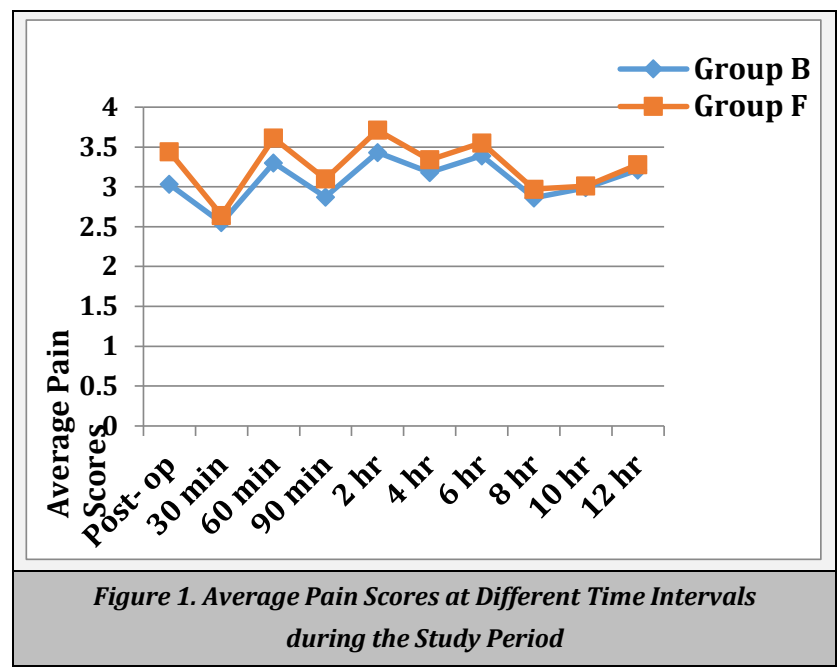

Figure 1, shows, no statistically significant difference between the two groups with respect to average pain scores as they are almost similar.

\begin{tabular}{|ccccc|}
\hline & Group B & Group F & T-Value & P-Value \\
\hline $\begin{array}{c}\text { Duration of analgesia } \\
\text { (minutes) }\end{array}$ & $\begin{array}{c}482.59 \pm \\
93.76\end{array}$ & $\begin{array}{c}174.13 \pm \\
84.91\end{array}$ & 15.42 & $<0.0001, \mathbf{S}$ \\
$\begin{array}{c}\text { Mean paracetamol } \\
\text { consumption per patient } \\
\text { (in mg) }\end{array}$ & $\begin{array}{c}126.66 \pm \\
18.70\end{array}$ & $\begin{array}{c}151.79 \pm \\
60.03\end{array}$ & 2.52 & $0.007, \mathrm{~S}$ \\
\hline Table 4. Duration of Analgesia and Mean Paracetamol Consumption \\
\hline
\end{tabular}

Table 4 shows, Group B had longer duration of analgesia as compared to Group F. Analgesia given by inj. fentanyl at a dose of $2 \mu \mathrm{g} \mathrm{Kg}^{-1}$ remained only for 3 - 4 hours and every patient in group $\mathrm{F}$ required rescue analgesia post-operatively. In either of the two groups, no patient required any additional analgesics except injection paracetamol. Similarly, inj. paracetamol consumption by each patient was significantly lower in group B as compared to Group F. During the study period of 12 hours, in Group F, a maximum of 2 and minimum of 1 rescue analgesics was required whereas, in Group B, a maximum of 1 and minimum of 0 rescue analgesics were required.

Intraoperative and postoperative pulse rate had no significant difference between the two groups and within each group. Fluctuations in mean arterial blood pressure were observed amongst individuals of fentanyl group but there were no variations in block group patients, who did not require any additional analgesia. Hence, these fluctuations may be due to inadequate analgesia. Episodes of airway obstruction due to secretions and bleeding was managed by suctioning and giving left lateral position. Complications like postoperative nausea vomiting, pruritis or desaturation has not been seen in any patients.

\section{DISCUSSION}

The way children suffer pain in postoperative period is same as that of adult. Pain is always subjective and is very difficult to quantify it, particularly in paediatric age group. ${ }^{14}$ No reliable indicator of pain in children is not available even today. ${ }^{15}$ Only older children with communicable ability can report or quantify pain.

In last few years, lots of improvement in awareness and treatment of pain in children has happened. Good postoperative pain relief leads to short recovery period with child and parents' satisfaction. This developed a momentum for refinement of various techniques for postoperative analgesia in children. ${ }^{14}$ Palatoplasty requires the child to be calm and pain free in the postoperative period to maintain the integrity of the delicate surgery.

Vigorous cry due to pain in postoperative period leads to wound gaping and respiratory complications, which results in delayed recovery and prolonged hospital stay. ${ }^{16}$ The risk of respiratory depression is less with the use of regional anaesthesia. ${ }^{17}$

Greater, lesser and nasopalatine nerve, branches of maxillary nerve, supplies the palate mucosa. Soft palate is supplied by lesser palatine nerve which lies in close proximity to greater palatine nerve in the canal, before the latter comes out of the foramen where we will be giving block.10 Local anaesthetic injection in foramen will blocked the maxillary nerve itself or its branches. Hence, greater palatine nerve block on both sides is effective for analgesia. In our study, both the groups were comparable regarding demographic data (age, weight, gender and duration of surgery).

Children who received block, showed smooth recovery from general anaesthesia as compared to those who received intravenous fentanyl for analgesia. Consistent with our results, Kamath et al. ${ }^{18}$ and Bösenberg and Kimble ${ }^{19}$ reported that awakening from anaesthesia was smooth and was rapid in regional anaesthesia compared to systemic opioids.

In our study, it was found that postoperative analgesia was better in group B when compared to group F. Jonnavithula et al. $^{20}$ and Abu Elyazed \& Mostafa ${ }^{21}$ also evaluated children undergoing palatoplasty under palatine block with $0.25 \%$ bupivacaine and found that it provided better pain relief postoperatively without anaesthetic sparing effect. They also noted that the low volume of the drug used for block lowers the risk of systemic toxicity and tissue distortion. A study conducted by Kamat et al. ${ }^{18}$, found that the rescue analgesic requirement was significantly less in block group and bupivacaine $0.25 \%$ used in block in their study gave analgesia up to 10 hours postoperatively. These results support the findings from our study. So, our study demonstrated that with greater palatine nerve block excellent postoperative analgesia 
was achieved with higher success rate and without any complications related to technique.

After palatoplasty, in postoperative period, because of narrowed air passage, there are chances of respiratory obstruction which may require airway interventions sometimes. ${ }^{22}$ No incidence of respiratory obstruction was noted in postoperative period in any child in our study. This may be due to selection of patients without other congenital anomalies, relatively shorter duration of surgery and better recovery of child from general anaesthesia. ${ }^{18}$

No significant difference was noted in intraoperative and postoperative heart rate between the two groups and within each group. Fluctuations in mean blood pressure which were may be due to inadequate analgesia were observed amongst individuals of fentanyl group but there were no variations in block group patients. Complications like postoperative nausea vomiting or desaturation has not been seen in any patients. Similar results were noted by other researchers. $6,18,23$. Limitation of our study includes short duration of analgesia of fentanyl which may have influenced the duration of analgesia as compared to much longer acting bupivacaine.

\section{CONCLUSIONS}

Bilateral greater palatine nerve block with inj. bupivacaine $0.25 \%$ provides good postoperative pain relief in children after palatoplasty, lasting for around 8 hours when compared to 3 to 4 hours following IV inj. fentanyl $2 \mu \mathrm{g}$. $\mathrm{Kg}^{-1}$. Palatine nerve block is safe, easy to perform, free of complications and it also avoids serious adverse events associated with IV opioids.

Financial or Other Competing Interests: None.

\section{REFERENCES}

[1] Strong EB, Buckmiller LM. Management of the cleft palate. Facial Plast Surg Clin North Am 2001;9(1):15-25.

[2] Jindal P, Khurana G, Dvivedi S, et al. Intra and postoperative outcome of adding clonidine to bupivacaine in infraorbital nerve block for young children undergoing cleft lip surgery. Saudi J Anaesth 2011;5(5):289-94.

[3] Doyle E, Hudson I. Anaesthesia for primary repair of cleft lip and cleft palate: a review of 244 procedures. Paediatric Anaesth 1992;2(2):139-45.

[4] Schettler D. Intra and postoperative complications in surgical repair of clefts in infancy. J Maxillofac Surg 1973;1(1):40-4.

[5] Reena, Bandyopadhyay KH, Paul A. Postoperative analgesia for cleft lip and palate repair in children. J Anaesthesiol Clin Pharmacol 2016;32(1):5-11.

[6] Obayah GM, Refaie A, Aboushanab 0, et al. Addition of dexmedetomidine to bupivacaine for greater palatine nerve block prolongs postoperative analgesia after cleft palate repair. Eur J Anaesthesiol 2010;27(3):280-4.
[7] Nicodemus HF, Ferrer MJ, Decastro L, et al. Bilateral infraorbital block with $0.5 \%$ bupivacaine as postoperative analgesia following cheiloplasty in children. Scand J Plast Reconstr Surg Hand Surg 1991;25:253-8.

[8] Malhotra N, Chanana C, Roy KK, et al. To compare the efficacy of two doses of intraperitoneal bupivacaine for pain relief after operative laparoscopy in gynecology. Arch Gynecol Obstet 2007;276(4):323-6.

[9] Zink W, Seif C, Bohl JRE, et al. The acute myotoxic effects of bupivacaine and ropivacaine after continuous peripheral nerve blockades. Anesth Analg 2003;97(4):1173-9.

[10] Malamed SF, Trieger N. Intraoral maxillary nerve block: an anatomical and clinical study. Anesth Prog 1983;30(2):44-8.

[11] Aldrete JA, Kroulik D. A postanaesthetic recovery score. Anaesth Analg 1970;49(6):924-34.

[12] Carney S, Kim A. Post anaesthesia recovery score revised. J Clin Anesth 1995;7:89-9.

[13] Merkel SI, Voepel-Lewis T, Shayevitz JR, et al. The FLACC: a behavioral scale for scoring postoperative pain in young children. Pediatr Nurs 1997;23(3):293-7.

[14] Grewal G, Garg K, Grewal A. Bilateral infraorbital nerve block versus intravenous pentazocine: a comparative study on post-operative pain relief following cleft lip surgery. J Clin Diagn Res 2015;9(5):4-6.

[15] Buttner W, Finke W. Analysis of behavioural and physiological parameters for the assessment of postoperative analgesic demand in newborns, infants and young children, a comprehensive report on seven consecutive studies. Paediatr Anaesth 2000;10(3):30318.

[16] Brenda G, Krane E. Treatment of pain in children. In: Healy T, Knight P, eds. Wylie and churchill davidson, a practice of anaesthesia. $7^{\text {th }}$ edn. London: Arnold 2003:1267-90.

[17] Hatch DJ. Analgesia in the neonate. Br Med J (Clin Res Ed) 1987;294(6577):920.

[18] Kamath MR, Mehandale SG, Raveendra US. Comparative study of greater palatine nerve block and intravenous pethidine for postoperative analgesia in children undergoing palatoplasty. Indian J Anaesth 2009;53(6):654-61.

[19] Bosenberg AT, Kimble FW. Infra orbital nerve block in neonates for cleft lip repair. Anatomical study and clinical application. Br J Anaesth 1995;74(5):506-8.

[20] Jonnavithula N, Durga P, Ramachandran G, et al. Efficacy of palatal block for analgesia following palatoplasty in children with cleft palate. Paediatr Anaesth 2010;20(8):727-33.

[21] Mohamed M. Elyazed A, Mostafa SF. Bilateral suprazygomatic maxillary nerve block versus palatal block for cleft palate repair in children: a randomized controlled trial. Egyptian J Anaesth 2018;34(3):83-8.

[22] Moore KL, Dalley AF, Agur AMR. Clinically oriented anatomy. $5^{\text {th }}$ edn. Philadelphia: Lippincott Williams \& Wilkins 2005: p. 1000.

[23] Mady RF, Zanaty OM, Shafshaak WM, et al. Bilateral greater palatine nerve block for perioperative analgesia in children undergoing palatoplasty. Res and Opinion in Anesthe and Intensive Care 2018;5(4):335-40. 